\title{
Carboplatin-gemcitabine in the treatment of elderly patients with non-small cell lung cancer: An outcome analysis
} \author{
Tassinari ${ }^{1 \text {,* }}$ \\ 1 Department of Oncology, City Hospital Rimini, AUSL Romagna, Italy \\ 2 Department of Internal Medicine, Arcispedale S.Anna, Ferrara, Italy \\ ${ }^{3}$ Department of Internal Medicine, AUSL Romagna, Italy \\ ${ }^{4}$ Department of Pneumology, AUSL Romagna, Italy
}

Manuela Fantini ${ }^{1}$, Lucia Stocchi ${ }^{1}$, Alessandra Affatato ${ }^{1}$, Maximilian Papi ${ }^{1}$, Sergio Sartori ${ }^{2}$, Giorgio Ioli ${ }^{3}$, Luigi Lazzari-Agli ${ }^{4}$ and Davide

\begin{abstract}
Introduction: To compare a novel carboplatin-gemcitabine (CG) schedule with gemcitabine (G) monochemotherapy in elderly patients with advanced NSCLC. Methods: The records of all the consecutive elderly patients referred to our Department of Oncology for advanced NSCLC were reviewed. Overall survival was the main outcome, time to progression, response rate and safety were the secondary end points. Results: Fifty patients (40 males and 10 females, mean age 75 years, range 68-87 years) were included into the analysis. 30 patients (60\%) were treated with the CG and 20 (40\%) with G. Median survival was 12.4 months for the entire population, and 14.9 and 5.3 months for CG and $G(p=0.043)$ respectively. $7(14 \%)$ and $2(4 \%)$ partial regressions were observed in CG and $G$ groups, $(p=0.085)$, with a median time to progression of 5.1 months for the entire population, and 7.3 and 3.5 months for $\mathrm{CG}$ and $\mathrm{G}(\mathrm{p}=0.237)$. Grade III neutropenia was observed in $8(16 \%)$ and $2(4 \%)$ patients treated with CG and G, respectively; grade IV neutropenia in $2(4 \%)$ and $2(4 \%)$ patients, grade III anemia in $2(4 \%)$ and $1(2 \%)$ patients, and grade III thrombocytopenia in 1(2) patient, respectively $(p=0.527)$. Grade II fatigue was observed in $5(10 \%)$ and $2(4 \%)$ patients, grade III diarrhea in $3(6 \%)$ and $1(2 \%)$ patients treated with CG and G, respectively $(p=0.722)$. Conclusions: Carboplatingemcitabine seems to be more effective that gemcitabine alone in elderly patients with advanced NSCLC, without any worsening of the safety profile. The data, extracted from an outcome analysis, confirm what has been observed in previous clinical trials.
\end{abstract}

Keywords: lung cancer; chemotherapy; carboplatin; gemcitabine

\section{Introduction}

In the recent years the treatment of locally advanced or metastatic non-small cell lung cancer (NSCLC) in elderly patients has changed, passing from a monochemotherapy to a polychemotherapy with platinum-containing regimens [1]. This attitude, progressively modified the clinical approach to elderly patients with locally advanced or metastatic lung cancer, identifies 2 different classes of patients for different chemotherapy (CT) approaches: patients fit, with good performance status, schedule, and patient moderately fit, or unfit, that can be candidate to monochemotherapy regimen with one of the $3^{\text {rd }}$ generation drugs such as vinorelbine, gemcitabine, or taxanes [1-2].

Likewise, many efforts have been made to define the best doublet to be used in fit elderly patients, and carboplatincontaining regimens (mainly carboplatin-paclitaxel or carboplatin-gemcitabine) seem to represent the most effective and best tolerated schedules for this class of frail patients [1-2, 4-5].

In our previous reports, we tested the activity and safety of a novel carboplatin-gemcitabine (CG) schedule in adult patients with advanced NSCLC, without any restriction due to age, performance status or disease extension. This schedule used reduced doses of both carboplatin (Area Under the Curve $4.5 \mathrm{mg} / \mathrm{ml} /$ minute on day 1 every 21 days) and gemcitabine ( $800 \mathrm{mg} / \mathrm{m}^{2}$ on day 1 and 8 every 21 days) [6-8], and showed an activity comparable with that reported in literature at standard doses [6-8].

In the present paper we report the final results of an outcome analysis that compared this novel schedule with gemcitabine $(\mathrm{G})$ monochemotherapy in elderly patients with advanced NSCLC.

*Corresponding author: Davide Tassinari, Department of Oncology, City Hospital Rimini, AUSL Romagna, Italy. Email: dtassinari@rimini.com

Received 12 August 2015 Revised 10 October 2015 Accepted 20 October 2015 Published 28 October 2015

Citation: Fantini M, Stocchi L, Affatato A, Papi M, Sartori S, Ioli G, Lazzari-Agli $\mathrm{L}$, Tassinari D. Carboplatin-gemcitabine in the treatment of elderly patients with non-small cell lung cancer: An outcome analysis. J Cancer Res Ther. 2015; 3(10):112-117. DOI:10.14312/2052-4994.2015-16

Copyright: (c) 2015 Fantini M, et al. Published by NobleResearch Publishers. This is an open-access article distributed under the terms of the Creative Commons Attribution License, which permits unrestricted use, distribution and reproduction in any medium, provided the original author and source are credited. 


\section{Methods}

\section{Patients' selection and treatment plan}

All the consecutive patients older than 65 years with locally advanced or metastatic NSCLC that referred to our Department of Oncology and were treated with chemotherapy were considered potentially eligible and included in the outcome analysis. All the patients had to be chemotherapy-naïve and no other concomitant neoplasm had to be active at the time of the enrollment. All the patients enrolled between January 2004 and December 2007 were treated with gemcitabine $1000 \mathrm{mg} / \mathrm{m}^{2}$ on days 1-8-15 every 28 days, and all patients enrolled between January 2008 and December 2013 were treated with carboplatin Area Under the Curve (AUC) $4.5 \mathrm{mg} / \mathrm{ml} / \mathrm{minute}$ on day 1 and gemcitabine $800 \mathrm{mg} / \mathrm{m}^{2}$ on days $1-8$ every 21 days. The change in our approach of treating elderly patients with locally advanced or metastatic NSCLC was due to the change in the recommendations of the main scientific societies [1-3]. It follows that no randomization process was applied to create the 2 groups of treatment, and all the differences that could favor an unbalance between the 2 groups reflect this change in the treatment strategy for elderly patients with lung cancer, and not to a random process.

The patients were treated with first-line chemotherapy (CG or $\mathrm{G}$ ) until the observation of further disease progression or unacceptable toxicity. They were assessed weekly for hematological and non-hematological toxicity, and after 3-4 courses of chemotherapy for clinical response. No patient was treated with more than 6 courses of chemotherapy, and no maintenance treatment was planned at the end of the 6 th course of treatment. Further systemic treatments at the time of disease progression were at discretion of the attending oncologist, and the datum was reported with descriptive aim.

For each patient, the following data were recorded: age at time of enrollment, histology (adenocarcinoma vs other histotypes of NSCLC), stage of the disease, ECOG Performance Status (PS), smoking status (active-smoker, past-smoker, non-smoker), G-CIRS Comorbidity Index, time of the beginning of first-line chemotherapy, response to chemotherapy using the RECIST criteria, time to disease progression, final status (dead or alive), date of death or last follow up, kind of chemotherapy (G or CG), second-line chemotherapy (if any), grade III-IV hematological and nonhematological toxicity.

\section{Outcome, safety and statistical analysis}

Mean age, sex, histology, stage of the disease, smoking status, ECOG PS, G-CIRS Comorbidity Index, and second line treatments were assessed in the entire population and in the $G$ and $C G$ groups with descriptive aim. The continuous and categorical variables were compared between the two groups using the Student t-test and the chi-square test, respectively. An alpha error of $5 \%$ was assumed as statistically significant.

Overall survival was the primary end-point of the trial; response rate, time to progression and safety of the two treatments were the secondary end-points. Survival was assessed from the beginning of chemotherapy to death; time to progression was assessed from the beginning of chemotherapy to clinical or instrumental evidence of disease progression using the RECIST criteria. Either overall survival or time to progression were analyzed for the entire population using the Kaplan Meyer non-parametric test. Median overall survival and time to progression were compared between the 2 groups using the univariate Logrank test, assuming an alpha error of $5 \%$ as statistically significant. All the patients were included in all statistical analyses, according with the intent-to-treat principle.

A multivariate analysis of overall survival was performed using the Cox Regression model and including into the analysis age, G-CIRS Comorbidity Index (continuous variables), first-line chemotherapy, ECOG PS (0 vs 1-2), histology (adenocarcinoma vs other hystotypes), stage of the disease (IIIB vs IV), and access to second line treatments (categorical variables). An alpha error of $5 \%$ was assumed as statistically significant.

Grade III and IV hematological and non-hematological toxicity observed in the entire population were reported with descriptive aim; a comparison between $G$ and CG groups was performed using the chi-square test, assuming an alpha error of $5 \%$ as statistically significant. The trial was notified to the local Ethical Committee.

\section{Results}

\section{Patients' characteristics}

Fifty patients (40 males and 10 females, mean age 75 years, range 68-87 years) were included into the analysis. Five patients (10\%) had IIIB stage of the disease, and 45 (90\%) IV stage. Twelve patients (24\%) were active smokers, 30 patients (60\%) were past-smokers, and 8 patients (16\%) were non-smokers. Thirty-two patients had adenocarcinoma (64\%), 12 squamous cell carcinoma (24\%), and 6 other NSCLC histotypes (12\%). ECOG PS was 0 in 34 patients (68\%), 1 in 14 (28\%), and 2 in 2 (4\%). The median G-CIRS for the entire population was 6 (range $0-17)$. Thirty patients (60\%) were treated with CG as firstline chemotherapy, and 20 (40\%) with G. Nineteen patients (38\%) were treated with second-line chemotherapy after disease progression.

CG and G group resulted well-matched for gender (25 vs 15 males, respectively; $p=0.47$ ), disease stage (26 vs 19 stage IV patients, respectively; $p=0.33$ ), histotype (20 vs 12 adenocarcinoma, and 6 vs 6 squamous cell carcinoma, respectively; $p=0.70$ ), smoker status ( 9 vs 3 active smokers, and 17 vs 13 past-smokers, $p=0.66$ ) G-CIRS indexes ( 6 vs 6 respectively, $p=0.845)$. Mean age was lower in $C G$ group than in the $G$ group ( 73 vs 77 years, $p=0.02$ ), PS was better in CG group than in G group (24 vs 10 patients with ECOG PS of 0 , and 6 vs 8 patients with ECOG PS of $1, p=0.043$, respectively), and more patients in CG group were treated with second-line CT after disease progression (16 vs 3 patients; $p=0.006$ ). All the data are detailed in Table 1.

\section{Outcome analysis}

All the patients enrolled were included in the analysis on the basis of the Intent to Treatment Principle. The median 
Table 1 Patients characteristics.

\begin{tabular}{|c|c|c|c|c|c|c|c|}
\hline \multirow[b]{2}{*}{ Number of patients (\%) } & \multicolumn{2}{|c|}{ Entire population } & \multicolumn{2}{|c|}{$\begin{array}{c}\text { Carboplatin-gemcitabine } \\
\text { group }\end{array}$} & \multicolumn{2}{|c|}{ Gemcitabine group } & \multirow{2}{*}{$\frac{p}{-}$} \\
\hline & 50 & $(100)$ & 30 & $(60)$ & 20 & $(40)$ & \\
\hline \multicolumn{8}{|l|}{ Gender } \\
\hline Male (\%) & 40 & $(80)$ & 25 & $(50)$ & 15 & (30) & \multirow{2}{*}{$0.47 * \star$} \\
\hline Female (\%) & 10 & $(20)$ & 5 & $(10)$ & 5 & $(10)$ & \\
\hline \multicolumn{8}{|l|}{ Stage } \\
\hline IIIB (\%) & 5 & $(10)$ & 4 & (8) & 1 & (2) & \multirow{2}{*}{$0.33^{* *}$} \\
\hline IV (\%) & 45 & (90) & 26 & $(52)$ & 19 & (38) & \\
\hline \multicolumn{8}{|l|}{ Smoker status } \\
\hline Past-smokers & 30 & 60 & 17 & 34 & 13 & 26 & \multirow[t]{2}{*}{$0.66 * *$} \\
\hline Non smokers & 8 & 16 & 4 & 8 & 4 & 8 & \\
\hline \multicolumn{8}{|l|}{ Histotype } \\
\hline Adenocarcinoma (\%) & 32 & $(64)$ & 20 & $(40)$ & 12 & $(24)$ & \multirow{3}{*}{$0.7^{* \star}$} \\
\hline $\begin{array}{l}\text { Squamous cell carcinoma } \\
(\%)\end{array}$ & 12 & $(24)$ & 6 & (12) & 6 & $(12)$ & \\
\hline Others (\%) & 6 & $(12)$ & 4 & (8) & 2 & (4) & \\
\hline \multicolumn{8}{|l|}{ ECOG performance status } \\
\hline $0(\%)$ & 32 & (68) & 24 & $(48)$ & 10 & $(20)$ & \multirow{3}{*}{$0.043 * *$} \\
\hline $1(\%)$ & 14 & $(28)$ & 6 & (12) & 8 & (16) & \\
\hline $2(\%)$ & 2 & (4) & 0 & $(0)$ & 2 & (4) & \\
\hline Second line treatments (\%) & 19 & (38) & 16 & (32) & 3 & (6) & $0.006 * *$ \\
\hline
\end{tabular}

Abbreviations: *= using the Student t-test; $* *=$ using the chi-square test; $* * *=$ using Mann-Whitney non-parametric test.

follow up for the entire population was 13.3 months. On the whole, 9 partial regressions (18\%), and 18 stabilizations $(36 \%)$ of the disease were observed, with a median time to progression of 5.1 months (95\% Confidence Interval $(\mathrm{Cl})$ : 1.4-8.7 months). At the time the data were censored, 36 patients were dead (72\%) with a median survival of 12.4 months (95\% Cl: 7.3-17.4 months) (Figure 1 and 2, and Table 2). Partial regression was observed in 7 patients (14\%) in CG group and in 2 patients (4\%) in C group; stable disease was observed in $13(26 \%)$ and 5 (10\%) patients, respectively $(p=0.085)$. Median time to progression was 7.3 months (95\% Cl: 4.9-9.7 months) in CG group and 3.5 months (95\% Cl: $2.1-4.8$ months) in $\mathrm{G}$ group $(\mathrm{p}=0.237)$, and $24(48 \%)$ and $12(24 \%)$ progression free patients after 3 months of follow up (Figure 3 and Table 2). Median survival was 14.9 months (range 5.9-23.8 months) and 5.3 months (range 0.6-9.9 months), respectively $(p=0.043)$, with 20 (40\%) and $6(12 \%)$ patients alive after 9 months of follow up (Figure 4 and Table 2 ).

In the multivariate analysis, the kind of first-line chemotherapy, and access to second-line chemotherapy resulted independent prognostic factors $(p=0.047$, and $p=0.004$ respectively); no significant role was observed for age $(p=0.078)$, ECOG Performance Status $(p=0.15)$, histology $(p=0.894)$, stage of the disease $(p=0.723)$, and G-CIRS Comorbidity Index $(p=0.868)$. The Hazard Ratio for kind of first-line chemotherapy (CG vs G), ECOG Performance Status (0 vs 1-2), stage of the disease (IIIB vs IV), histology (adenocarcinoma vs other histotypes), use of

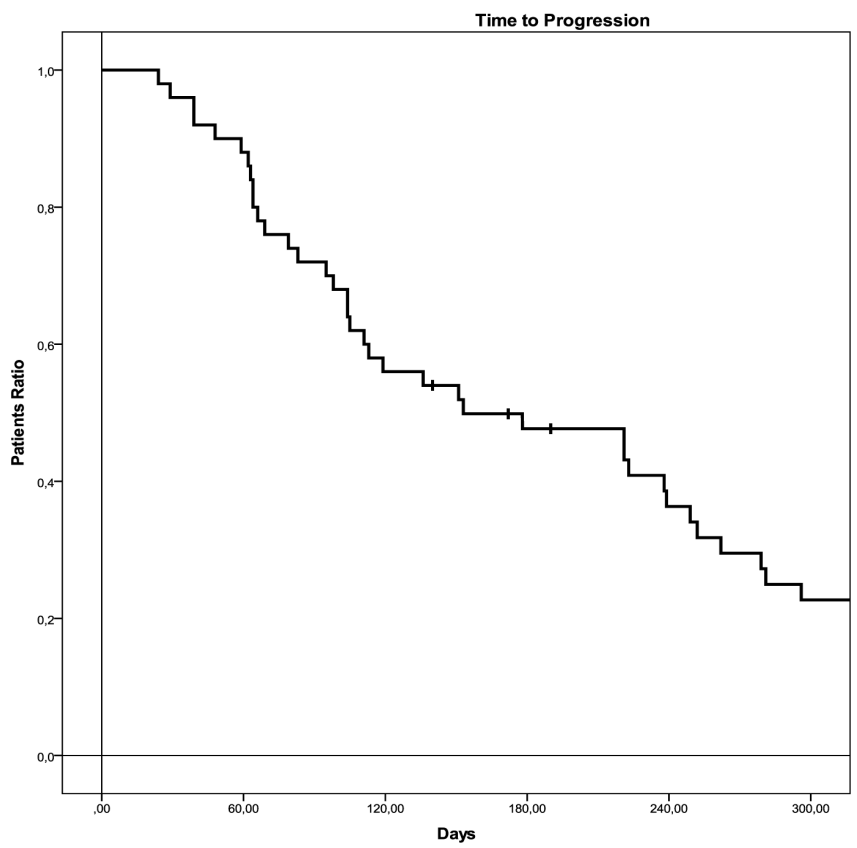

Figure 1 Time to progression for the entire population. 


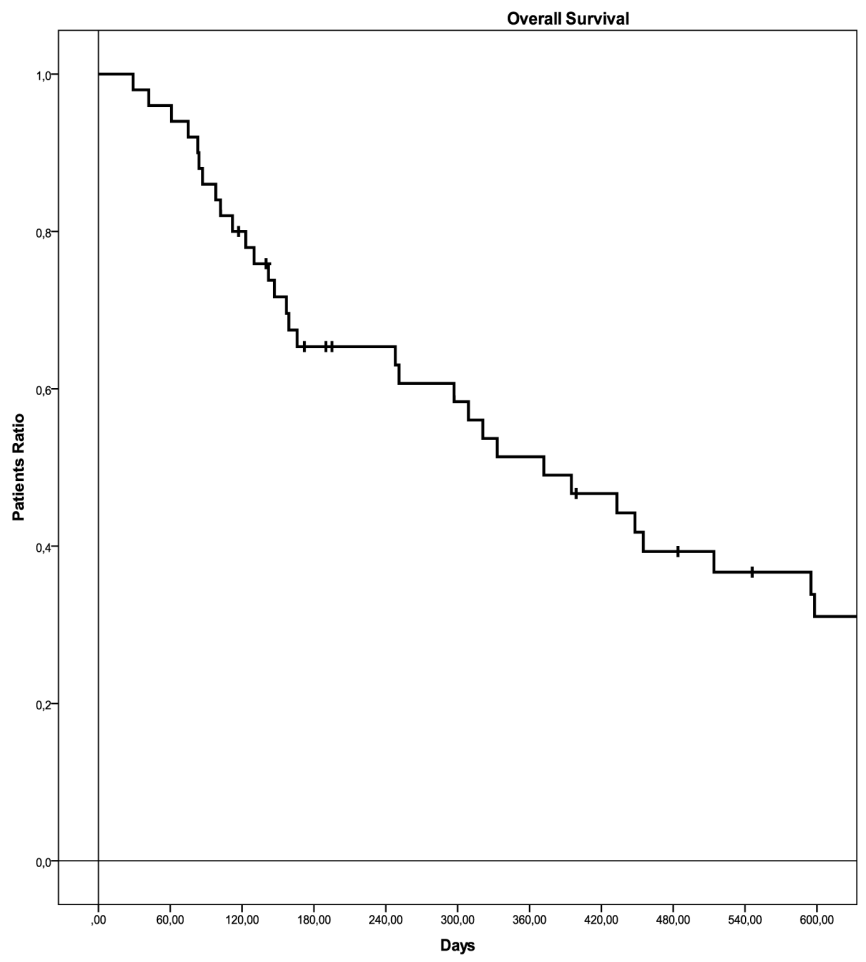

Figure 2 Overall survival for the entire population.

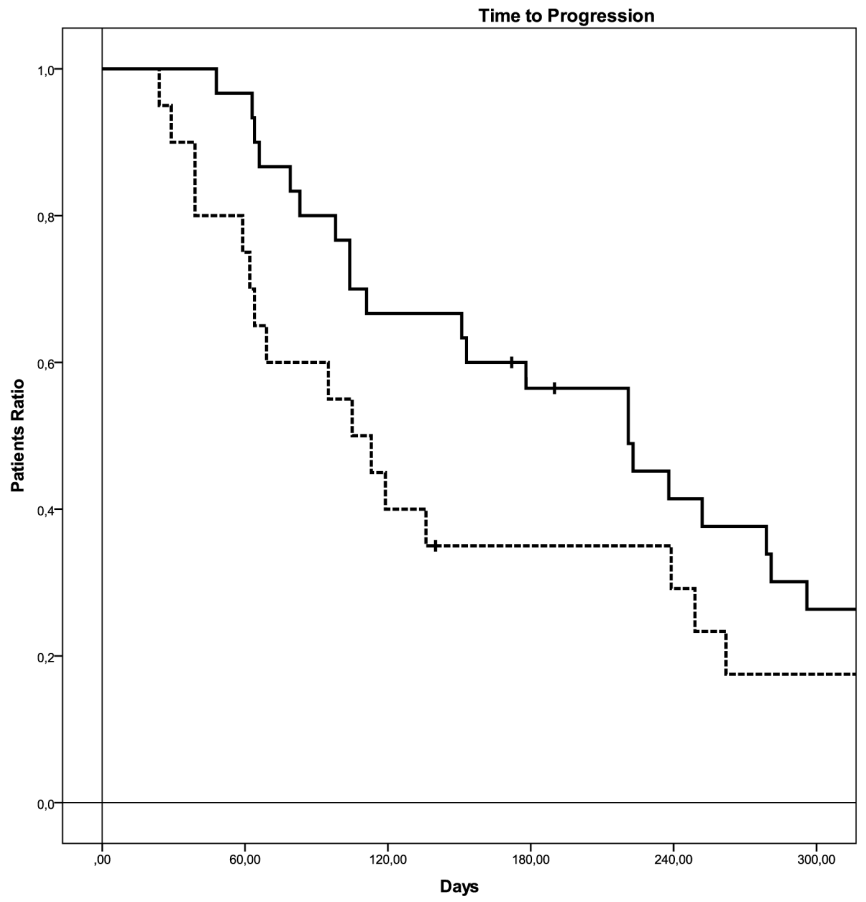

Abbreviations: = Carboplatin-gemcitabine group; -------- = Gemcitabine group

Figure $\mathbf{3}$ Time to progression in the two groups of treatment.

second-line chemotherapy were respectively 0.46 (95\% Cl: 0.248-0.991, $p=0.047), 0.58$ (95\%Cl: 0.276-1.218, $p=0.15)$, 0.804 (95\%Cl: $0.24-2.692, p=0.723), 1.058$ (95\%Cl: $0.463-$ 2.418, $p=0.894), 0.269$ (95\%Cl: $0.11-0.657, p=0.004)$. All the data are detailed in Figure 5.

\section{Safety}

Both CG and G were well tolerated with few grade III-IV side effects, defined according with the CTCAE 4.03 [9].

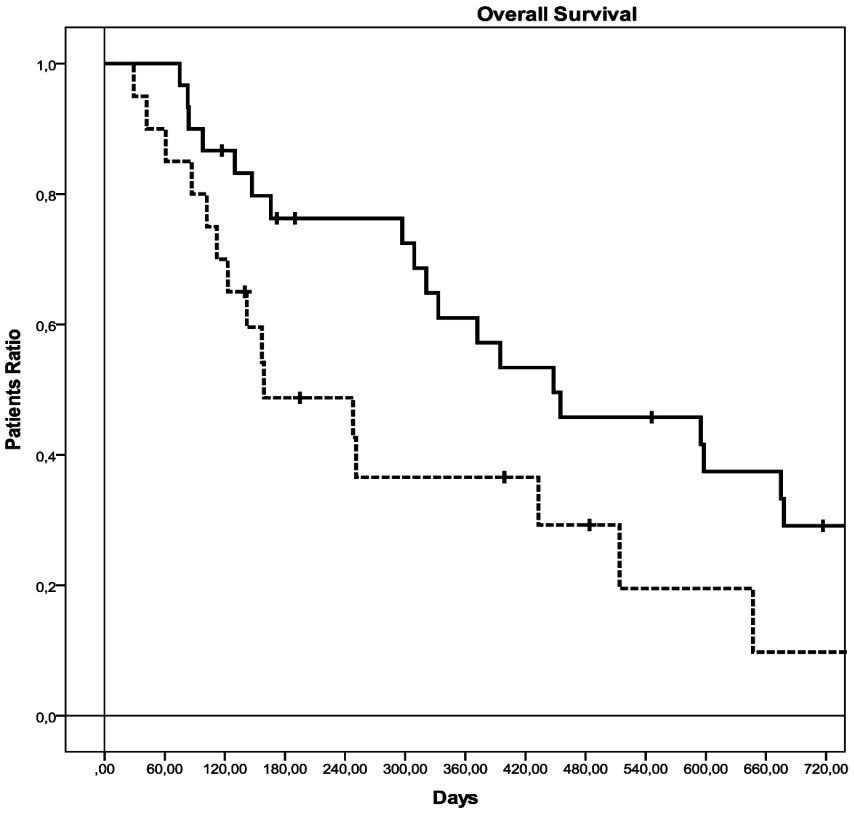

Abbreviations: = Carboplatin-gemcitabine group; $=$ Gemcitabine group

Figure $\mathbf{4}$ Overall survival in the two groups of treatment.

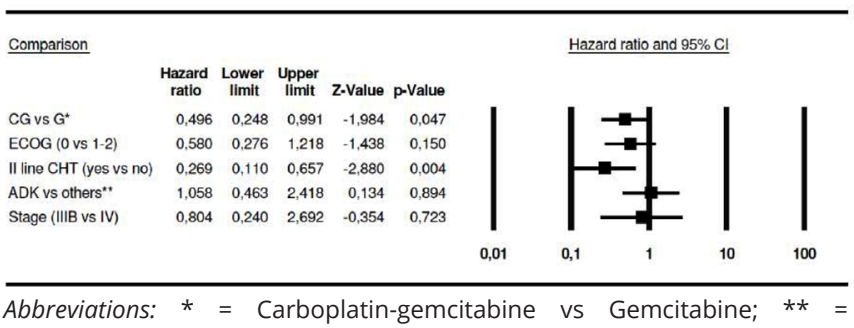
Adenocarcinoma vs other histotypes.

Figure 5 Hazard ratio for the different sub-groups of patients.

Grade III neutropenia was observed in 10 patients (20\%), grade IV non-febrile neutropenia in 4 patients $(8 \%)$, grade III anemia in 3 patients (6\%), grade III piastrinopenia in 1 patient (2\%). Likewise, grade II fatigue was observed in 7 patients (14\%), and grade III diarrhea in 4 patients (8\%). No significant difference was observed in severe side effects rate between CG and $G(p=0.527$ and $p=0.722$, respectively) (Table 3).

\section{Discussion}

After the first experiences of Gridelli and co-workers [10-11], who introduced chemotherapy in the treatment of elderly patients with advanced NSCLC, many efforts have been made to identify the best schedules and the subtypes of elderly patients who are likely to benefit by the treatment [1]. Two orders of considerations can be extracted from the reports published in literature: can platinum containing regimens improve the outcome of elderly patients with NSCLC, without compromising the safety of a treatment, the aim of which remains uniquely palliative, and what subtypes of elderly patients can be considered eligible for a palliative chemotherapy, avoiding either it is too extensive or a too restrictive use?

There are some reports in literature that deal with either the role of doublets in the treatment of elderly patients 
Table 2 Main outcomes for the entire population and in the 2 different groups of treatment.

\begin{tabular}{|c|c|c|c|c|c|c|c|}
\hline & \multicolumn{2}{|c|}{$\begin{array}{l}\text { Entire population } \\
(50)\end{array}$} & \multicolumn{2}{|c|}{$\begin{array}{c}\text { Carboplatin-gemcitabine group } \\
(30)\end{array}$} & \multicolumn{2}{|c|}{ Gemcitabine group (20) } & $p$ \\
\hline Complete regression (\%) & 0 & (0) & 0 & (0) & 0 & (0) & \multirow{4}{*}{$0.085^{* *}$} \\
\hline Partial regression (\%) & 9 & (18) & 7 & (14) & 2 & (4) & \\
\hline Stable disease $(\%)$ & 18 & (36) & 13 & $(26)$ & 5 & (10) & \\
\hline Disease progression (\%) & 23 & $(46)$ & 10 & (20) & 13 & (26) & \\
\hline Time to progression (CI95\%) & 5.1 months* & $\begin{array}{l}(1.4-8.7 \\
\text { months)* }\end{array}$ & 7.3 months & $\begin{array}{l}(4.9-9.7 \\
\text { months) }\end{array}$ & 3.5 months & $\begin{array}{l}(2.1-4.8 \\
\text { months) }\end{array}$ & $0.237 * * *$ \\
\hline 3-month progression-free patients (\%) & 36 & $(72)$ & 24 & $(48)$ & 12 & (24) & \\
\hline Median survival (CI95\%) & $\begin{array}{l}12.4 \\
\text { months* }\end{array}$ & $\begin{array}{l}\text { 7.3-17.4 } \\
\text { months* }\end{array}$ & 14.9 months & $\begin{array}{l}(5.9-23.8 \\
\text { months })\end{array}$ & 5.3 months & $\begin{array}{l}(0.6-9.9 \\
\text { months) }\end{array}$ & $0.043^{* * *}$ \\
\hline 9-months alive patients (\%) & 26 & (52) & 20 & $(40)$ & 6 & $(12)$ & \\
\hline
\end{tabular}

Abbreviations: *= using the Kaplan Meyer non-parametric test; **= using the chi-square test; $* * \star=$ using the Log-Rank non-parametric test and comparing CG vs $\mathrm{G} ; \mathrm{Cl} 95 \%=95 \%$ Confidence Interval

Table 3 Side effects in the entire population and in the two groups of treatment.

\begin{tabular}{|c|c|c|c|c|c|c|c|}
\hline \multirow{2}{*}{ Hematological side effects* } & \multicolumn{2}{|c|}{$\begin{array}{c}\text { Entire population } \\
(50)\end{array}$} & \multicolumn{2}{|c|}{$\begin{array}{c}\text { Carboplatin-gemcitabine } \\
\text { group (30) }\end{array}$} & \multicolumn{2}{|c|}{ Gemcitabine group (20) } & \multirow[t]{2}{*}{$p$} \\
\hline & & & & & & & \\
\hline Grade III neutropenia & 10 & 20 & 8 & 16 & 2 & 4 & \multirow{4}{*}{$0.527 * *$} \\
\hline Grade IV neutropenia & 4 & 8 & 2 & 4 & 2 & 4 & \\
\hline Grade III anemia & 3 & 6 & 2 & 4 & 1 & 2 & \\
\hline Grade III thrombocytopenia & 1 & 2 & 1 & 2 & 0 & 0 & \\
\hline \multicolumn{8}{|l|}{ Non-hematological side effects* } \\
\hline Grade II fatigue & 7 & 14 & 5 & 10 & 2 & 4 & \multirow{2}{*}{$0.722 * \star$} \\
\hline Grade III diarrhea & 4 & 8 & 3 & 6 & 1 & 2 & \\
\hline
\end{tabular}

Abbreviations: *= according with the CTCAE 4.01 [9]; **= using the chi-square test.

with NSCLC, or the role of cisplatin and carboplatin in the doublets [1]. Although cisplatin is more effective than carboplatin in the treatment of advanced NSCLC [12], its safety profile is not always suitable for elderly patients with comorbidities frequently needing the concomitant use of other drugs. The reduced renal and gastrointestinal toxicity, and the possibility of avoiding a strong hydration, make carboplatin more preferable in the treatment of frail patients with advanced cancer.

Many trials investigated the combination of carboplatin with $3^{\text {rd }}$ generation antineoplastic agents (mainly gemcitabine or paclitaxel), and nowadays carboplatin-gemcitabine or carboplatin-paclitaxel seem to represent the treatment of choice for elderly, fit patients with advanced NSCLC [1, 13$16]$.

In our previous experiences we identified a novel schedule in which we use lower doses of carboplatin and gemcitabine in respect with those reported in the most part of the schedules of literature, whose activity and safety seemed to be comparable with those of literature [6-8]. In the actual experience, we hypothesize a novel role of our lowdoses schedule for the treatment of elderly patients with advanced NSCLC.

On the whole, some experiences reported the use of cisplatin-containing doublets in well selected subgroups of elderly fit patients with good performance status, and similar trials are still in progress [16-19]. However, at present cisplatin-containing doublets cannot be considered the standard treatment for elderly patients with advanced NSCLC, and they remain just a hypothetical option for well selected patients [17-18].

In our study, we compared the outcome and safety of two different regimens in elderly patients with advanced NSCLC. The choice of the different schedules depended uniquely on our change of attitude from G to CG in the treatment of elderly patients with NSCLC in the last years, and the inclusion of the patients in monochemotherapy group or in the carboplatin-containing doublet group was not due to any other consideration. It follows that our experience represents an outcome analysis and not a comparative clinical trial, and our results must be considered uniquely descriptive. The datum merits to be adequately underlined. The retrospective analysis of the outcomes of 2 different populations of patients and the lack of any process of randomization in creating the 2 comparative groups exclude any final consideration other than the description of the outcomes of different treatments in different populations. Likewise, the lack of any randomization justifies the unbalance of the 2 groups, with the relevant differences in terms of mean age, ECOG performance status or use of second line treatments. In particular, it has to be clearly kept in mind how the attitude of oncologist and scientific societies is changed in the last years about the choice of treating elderly patients with NSCLC, and how their opinion is changed about age, performance status limitations, or indication to second line treatments 
[2-3]. On the whole, our experience confirms both that a carboplatin-containing regimen such as CG can improve overall survival in elderly patients with advanced NSCLC, as suggested by recent reports [1, 3, 14], and that our attitude in treating elderly patients with advanced NSCLC, according with literature data, has changed during the observational time, with an increasing attitude in treating more aged patients or patients that progress after first line treatment. Likewise, the multivariate analysis has shown that this regimen represents an independent prognostic factor in the entire population of patients, confirming in an outcome analysis what is described in literature in favor of carboplatin-containing combination chemotherapy [13-15]. The improvement in overall survival (the primary end-point of our study) was obtained despite no difference in both response rate and time to progression observed between CG and G schedules. It could be hypothesized that the doublet could change by itself the natural history of the disease, improving overall survival without influencing clinical response or time to progression.

Furthermore, also the use of second-line CT resulted an independent prognostic factor in the multivariate analysis confirming that it should be offered to all the patients whenever their clinical conditions allow a treatment after disease progression [1].

As largely detailed in the previous parts of the paper, our study has several limits. First, our data are extracted from a patient-series that included all the consecutive elderly patients with advanced NSCLC, and the two groups of patients were defined uniquely on the basis of our change in attitude of treating this class of patients. Second, our experience is based on just an outcome analysis. It follows that the comparison between G and CG in terms of activity, efficacy and safety has uniquely a descriptive aim, and can onlygeneratehypotheses aboutwhat is the better treatment for elderly fit patients with NSCLC. Furthermore, the two groups of treatment were not generated by randomization. Consequently, some biases could have influenced both the composition of the two groups and the final results. Finally, our outcome analysis was planned before the advent of the EGFR-typization and the introduction of the tyrosinekinase inhibitors in clinical practice (in particular for the histotype adenocarcinoma). Therefore, our data are likely to give only a minor contribute to the present clinical debate, because the tyrosine-kinase inhibitors could play a relevant role in the first-line approach to patients with adenocarcinoma histotype and EGFR-mutated expression $[1,20]$. However, in our multivariate analysis the histotype did not seem to play any significant prognostic role, and only few patients enrolled into our trial could probably have benefit by tyrosine-kinase inhibitors.

\section{Conclusion}

Carboplatin-gemcitabine seems to be more effective than gemcitabine in elderly fit patients with advanced NSCLC. In this subgroup of patients, the carboplatin-containing doublet is an independent prognostic factor that improves overall survival. The schedule, that we showed to be active and effective in adult patients [6-8], seems to maintain its efficacy even in elderly patients with NSCLC, without worsening its safety profile. Nevertheless, further trials are probably needed to definitively validate this novel schedule in the treatment of fit elderly patients with advanced NSCLC.

\section{Conflict of interest}

The authors declare no conflict of interest.

\section{References}

[1] Pallis AG, Gridelli C, Wedding U, Faivre-Finn C, Veronesi G, et al. Management of elderly patients with NSCLC; updated expert's opinion paper: EORTC Elderly Task Force, Lung Cancer Group and International Society for Geriatric Oncology. Ann Oncol. 2014; 25(7):1270-1283.

[2] National Comprehensive Cancer Network. Senior adult oncology. Available at: http://www.nccn.org/professionals/physician_gls/pdf/ senior.pdf

[3] Azzoli CG, Temin S, Aliff T, Baker S Jr, Brahmer J, et al. 2011 focused updated of 2009 American Society of Clinical Oncology clinical practice guideline update on chemotherapy for stage IV non small cell lung cancer. J Clin Oncol. 2011; 29(28):3825-3831.

[4] Quoix E, Zalcman G, Oster JP, Westeel V, Pichon E, et al. Carboplatin and weekly paclitaxel doublet chemotherapy compared with monotherapy in elderly patients with advanced non-small-cell lung cancer: IFCT-0501 randomised, phase 3 trial. Lancet. 2011; 378(9796):1079-1088.

[5] Socinski MA, Langer CJ, Okamoto I, Hon JK, Hirsh V, et al. Safety and efficacy of weekly nab®-paclitaxel in combination with carboplatin as first-line therapy in elderly patients with advanced non-small-cell lung cancer. Ann Oncol. 2013; 24(2):314-321.

[6] Tassinari D, Drudi G, Panzini I, Pasini G, Arcangeli V, et al. Combination chemotherapy of carboplatin and gemcitabine against solid tumors: a phase I trial. Int J Clin Oncol. 2001; 6:279-283.

[7] Tassinari D, Fochessati F, Arcangeli V, Sartori S, Agostini V, et al. Carboplatin and gemcitabine in the palliative treatment of stage IV non small cell lung cancer: definitive results of a phase II trial. Tumori. 2004; 90(1):54-59.

[8] Tassinari D, Arcangeli V Fochessati F, Drudi G, Panzini I, et al. Carboplatin gemcitabine combination as first line chemotherapy in advanced Non Small Cell Lung Cancer. Proc. XXXVII ASCO meeting. J Clin Oncol. 2001; 20(2):251b.

[9] National Cancer Institute. Common Terminology Criteria for Adverse Events (CTCAE). Version 4.0. Published: May 28, 2009. Available at: http://evs.nci.nih.gov/ftp1/CTCAE/CTCAE_4.03_2010-2006-14_ QuickReference_8.5x11.pdf

[10] Effects of vinorelbine on quality of life and survival of elderly patients with advanced non-small-cell lung cancer. The Elderly Lung Cancer Vinorelbine Italian Study Group. J Natl Cancer Inst. 1999; 91(1):66-72.

[11] Gridelli C, Perrone F, Gallo C, Cigolari S, Rossi A, et al. Chemotherapy for elderly patients with advanced non-small-cell lung cancer: the Multicenter Italian Lung Cancer in the Elderly Study (MILES) phase III randomized trial. J Natl Cancer Inst. 2003; 95(5):362-372.

[12] Ardizzoni A, Boni L, Tiseo M, Fossella FV, Schiller JH, et al. Cisplatinversus carboplatin-based chemotherapy in first-line treatment of advanced non-small-cell lung cancer: an individual patient data metaanalysis. J Natl Cancer Inst. 2007; 99(11):847-457.

[13] Sederholm C, Hillerdal G, Lamberg K, Kolbeck K, Dufmats M, et al. Phase III gemcitabine plus carboplatin versus single-agent gemcitabine in the treatment of locally advanced or metastatic non-small-cell lung cancer: the Swedish Lung Cancer Study Group. J Clin Oncol. 2005; 23(33):83808388.

[14] Russo A, Rizzo S, Fulfaro F, Adamo V, Santini D, et al. Gemcitabinebased doublets versus single-agent therapy for elderly patients with advanced non small cell lung cancer. Cancer. 2009; 115(9)1924-1931.

[15] Ramalingam S, Perry MC, La Rocca R, Rinaldi D, Gable PS, et al. Comparison of outcomes for elderly patients treated with weekly paclitaxel in combination with carboplatin versus the standard 3-weekly paclitaxel and carboplatin for advanced non small cell lung cancer. Cancer. 2008; 113(3):542-546.

[16] Kusagaya H, Inui N, Karayama M, Nakamura Y, Kuroishi S, et al. Biweekly combination therapy with gemcitabine and carboplatin compared with gemcitabine monotherapy in elderly patients with advanced non-small-cell lung: a randomized, phase II study. Lung Cancer. 2012; 77(3):550-555.

[17] Langer CJ, Manola J, Bernardo P, Kugler JW, Bonomi P, et al. Cisplatinbased therapy for elderly patients with advanced non-small-cell lung cancer: implications of Eastern Cooperative Oncology Group 5592, a randomized trial. J Natl Cancer Inst. 2002; 94(3):173-181.

[18] Gridelli C, Paione P, Illiano A, Piantedosi FV, Favaretto A, et al. Cisplatin plus gemcitabine or vinorelbine for elderly patients with advanced non-small-cell lung cancer: the MILES-2P studies. J ClinOncol. 2007; 25(29):4663-4669.

[19] clinicaltrials. US National Institutes of Health. Available at: https:// clinicaltrials.gov/ct2/results?term =lung + cancer + and +elderly+and + cisplatin\&Search $=$ Search

[20] Meoni G, Cecere FL, Lucherini E, Di Costanzo F. Medical treatment of advanced non-small cell lung cancer in elderly patients: a review of the role of chemotherapy and target agents. J Geriatr Oncol. 2013; 4(3):282-290. 